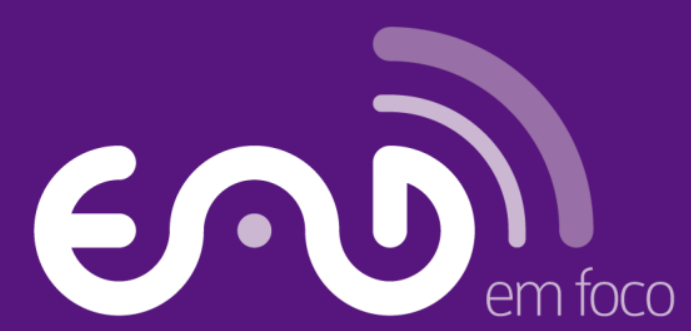

Revista Científica em Educação a Distância

\title{
Vol.5, №3
}

Julho - dezembro de 2015

Fundação CECIERJ

www.eademfoco.cecierj.edu.br

ISSN 2177 - 8310

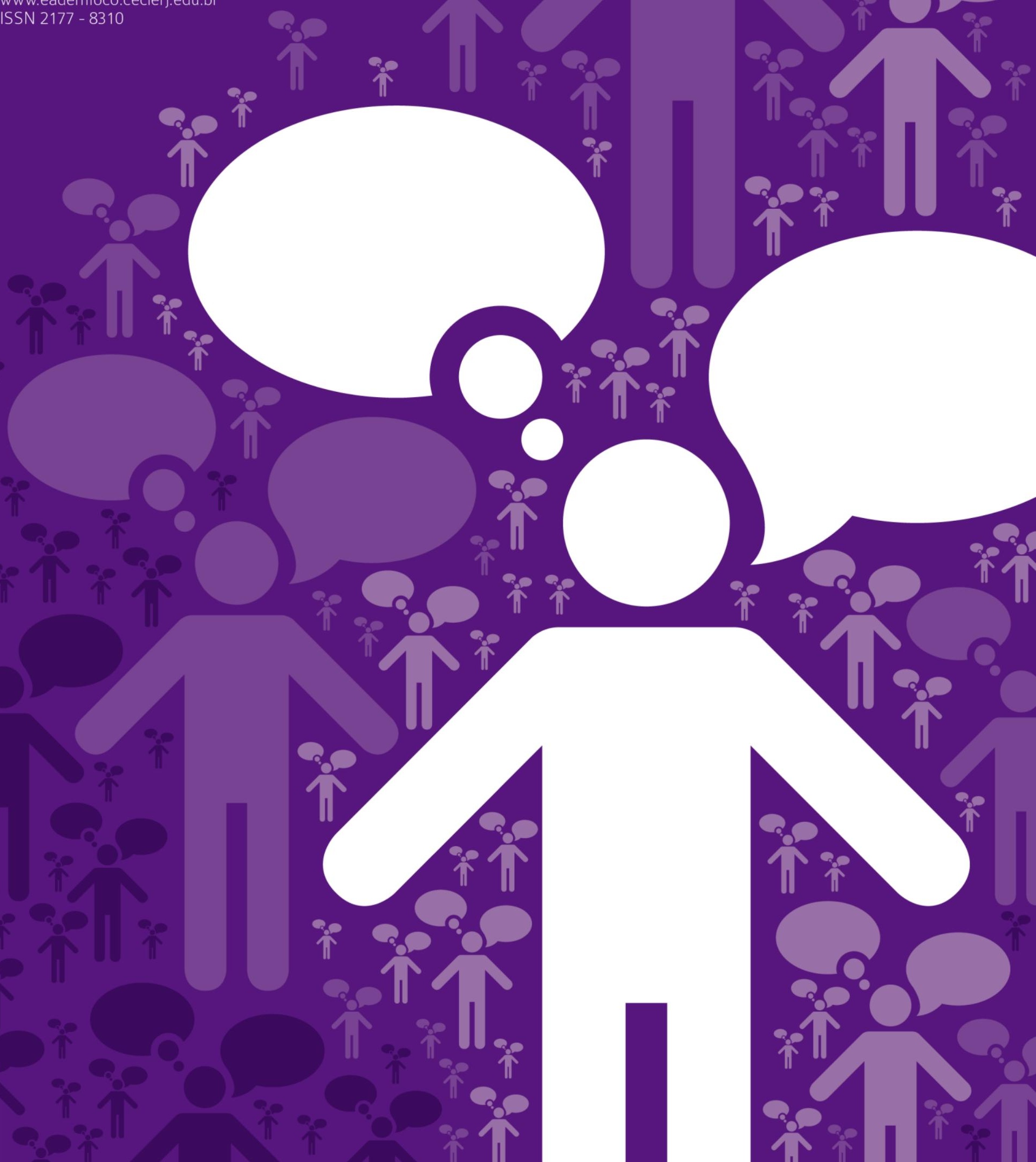




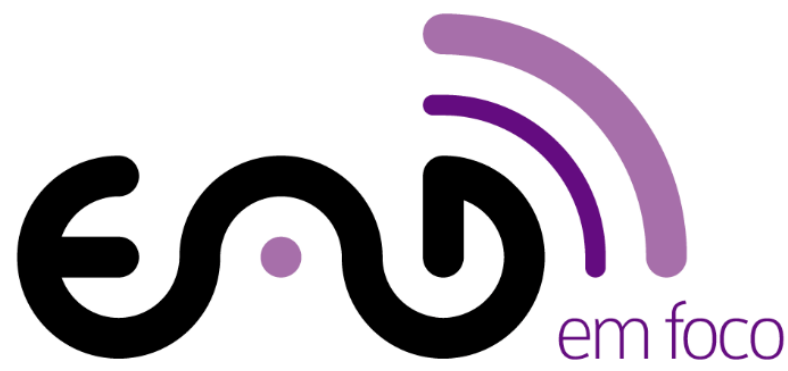

Revista Científica em Educação a Distância

A revista EAD em Foco é uma publicação científica da Fundação Centro de Ciências e Educação Superior a Distância do Estado do Rio de Janeiro (CECIERJ). 
சกலி

Revista Cientifica em Educaçăo a Distância

A Revista EAD em Foco é uma publicação científica em formato eletrônico, com periodicidade semestral, da Fundação Centro de Ciências e Educação Superior a Distância do Estado do Rio de Janeiro (CECIERJ). Tem como principal finalidade difundir a produção acadêmica de pesquisadores da área de educação a distância (EAD), inseridos em instituições do Brasil e do exterior.
GOVERNO DO ESTADO DO RIO DE JANEIRO

Governador

Luiz Fernando Pezão

Secretário de Estado de Ciência e Tecnologia

Gustavo Reis Ferreira

FUNDAÇÃO CECIERJ

Diretoria de Extensão

Rua da Ajuda, 5, $15^{\circ}$ andar - Centro - Rio de Janeiro, RJ - CEP 20.040-000

Tel.: (21) 2333-1080 | Fax: (21) 2568-0725

Presidente

Carlos Eduardo Bielschowsky

Vice-Presidente de Educação Superior a Distância

Masako Oya Masuda

Vice-presidente Científica

Mônica Santos Dahmouche
EAD em Foco: Revista Científica em Educação a Distância Fundação Centro de Ciências e Educação Superior a Distância do Estado do Rio de Janeiro (CECIERJ)

Diretoria de Extensão - Vol. 5, № 2 (2015) - Rio de Janeiro

Diretoria de Extensão, 2015 - Semestral

ISSN 21778310

1. Educação-Periódicos.

2. Educação a Distância - Periódicos.

3. Políticas Públicas em Educação-Periódicos

I. Fundação Centro de Ciências e Educação

Superior a Distância do Estado do Rio de Janeiro.

Diretoria de Extensão.

Responsabilidade Institucional

Masako Oya Masako, Universidade Federal do Rio de Janeiro

Elizabeth Soares Bastos, Fundação CECIERJ

\section{Editores}

Esteban Lopez Moreno (coordenador), Fundação CECIERJ

Luiz Gustavo Ribeiro Rolando, Instituto Oswaldo Cruz

\section{Revisão de Texto}

Alexandre Alves, Fundação CECIER

Diana Castellani, Fundação CECIERJ

Maria das Graças Ramos, Brasil

Lícia Matos, Fundação CECIERJ

Maria Elisa Silveira, Fundação CECIERJ

Vittorio Lo Bianco, Fundação CECIERJ

\section{Editor de Layout}

Fábio Gouvêa Andrezo Carneiro, Fundação CECIERJ
Conselho Editorial Científico

Agnaldo da Conceição Esquincalha, PUC-Rio

Alcenir Soares Reis, UFMG

André Luís Alice Raabe, Universidade do Vale do Itajaí Beatriz Cintra Martins, Instituto Oswaldo Cruz

Benjamin Carvalho Teixeira Pinto, UFRRJ

Cristina Maia Cristina Oliveira Maia, IBqM/ UFRJ

Daniel Fábio Salvador, Fundação CECIERJ

Dirceu Esdras Teixeira, INES

Edméa Oliveira Santos, UERJ

Fernanda Claudia Alves Campos, UFJF

Francisco José Figueiredo Coelho, UERJ

Guaracira Gouvêa, UNIRIO - UNIRIO

Joaquim Fernando Silva, UFRJ

José Ailton Feitosa, UFC

João Mattar, Universidade Anhembi Morumbi

Maria Cristina Pfeiffer Fernandes, Fundação CECIERJ

Marilene Santana dos Santos Garcia, PUC-SP

Marlene Benchimol, Universidade Santa Úrsula

Mauro Cavalcante Pequeno, UFC

Neide dos Santos, UER

Rafael Moreira Lima, UNB

Roberta Flávia Ribeiro Rolando Vasconcellos, Unigranrio

Samira Pirola Santos Mantilla, Fundação CECIERJ

Wanderlucy Czeszak, Universidade Anhembi Morumbi 


\section{Artigos Originais}

A POLIFONIA NO DISCURSO PEDAGÓGICO DO TUTOR

Maira Penteado

A IMPORTÂNCIA DO AMBIENTE VIRTUAL DE APRENDIZAGEM EM UM CURSO DE GRADUAÇÃO COM BASE NAS PERCEPÇÕES DE ALUNOS A DISTÂNCIA

Thaís Tenório, Marilda Adlong Laudelino, André Tenório

O EMPREGO DO E-MAIL E DO FACEBOOK NA EDUCAÇÃO A DISTÂNCIA COM BASE NAS PERCEPÇÕES DE ALUNOS E EGRESSOS

Thaís Tenório, Taís Rodrigues Marques, Nívia Patterson, André Tenório

45

FORMAÇÃO DE PROFESSORES NA EDUCAÇÃO A DISTÂNCIA E A PRÁTICA REFLEXIVA Nádia França Teixeira, Patrícia Vasconcelos Almeida

A EAD NO BRASIL E O PROCESSO DE DEMOCRATIZAÇÃO DO ACESSO AO ENSINO SUPERIOR: DIÁLOGOS POSSÍVEIS

Felipe Augusto Fernandes Borges

AS NOVAS CONDIÇÕES SÓCIO TÉCNICAS PARA UMA EAD 2.0

Rubem Damião Soares Nogueira

103

EDUCAÇÃO A DISTÂNCIA (EAD): PROCESSOS DE MEDIAÇÃO E USO DAS TECNOLOGIAS EM UMA ABORDAGEM TRANSDISCIPLINAR

Daniela Da Costa Britto Pereira Lima, Lívia Soares de Lima Sousa 


\section{Estudos de Caso}

ESTÁGIO DE DOCÊNCIA E PROJETOS DE EXTENSÃO NUMA LICENCIATURA EM LÍNGUA ESTRANGEIRA EM EAD NO ESPÍRITO SANTO

Mariza Silva de Moraes

136

PERCEPÇÕES DE TUTORES SOBRE AS COMPETÊNCIAS COMPORTAMENTAIS

André Tenório, Cláudio Oliveira da Gama, Thaís Tenório 
5 anos a Revista EAD em Foco lançava sua primeira edição, como resultado do esforço de diversos profissionais engajados em difundir a produção acadêmica da educação a distância, especialmente no Brasil e na América Latina. Para uma revista científica tradicional, não é tanto tempo, mas rapidamente nos firmamos como uma das publicações mais sólidas, dinâmicas e relevantes da área. Não foram poucos os motivos e desafios.

A partir deste ano a revista passou a contar com o Digital Object Identifier System (DOI), sistema que fornece infraestrutura técnica para o registro e uso de identificadores persistentes interoperáveis para uso em redes digitais. O DOI é um código utilizado para identificar exclusivamente determinado conteúdo utilizado especialmente para documentos eletrônicos, como artigos científicos publicados em periódicos acadêmicos. De forma prática, a utilização do DOI auxilia na identificação de um artigo, possibilitando a sua quantificação e divulgação quando citado em outros documentos.

Para facilitar esta operação (e outras!), passamos a contar com uma das versões mais atualizadas do sistema SEER/OJS, principal software para a construção e gestão de publicações periódicas eletrônicas no mundo. Dessa forma, todas as nossas publicações ganharam maior visibilidade e facilidades técnicas, como exportação de citações, comentários e navegabilidade. Junto com a atualização da versão, passamos a dispor de uma reforma de identidade visual, tornando a revista mais moderna e funcional. Prestamos aqui homenagem especial ao editor de leiaute Fábio Gouvêa Carneiro, pela criatividade demonstrada na criação dos novos leiaute e logotipo da revista, bem como das capas dos números publicados ao longo deste ano.

Outro objetivo alcançado era vincular a revista em novas bases de dados. Atualmente a EAD em Foco encontra-se indexada nas seguintes bases de dados: CrossRef, IBICT, Latindex, Index Copernicus Internacional, BASE - Bielefeld Academic Search Engine, Diadorim, Issuu e Google Acadêmico, e não vamos parar por aí. A indexação em importantes bases de dados possibilita maior divulgação dos artigos, ao mesmo tempo que confere credibilidade à revista, uma vez que é um critério central na avaliação da Capes para posicionamento de um periódico científico dentro dos estratos de cada área de pesquisa.

No mês de outubro, a Capes anunciou os resultados de atualização do Qualis periódicos, apresentando a classificação dos periódicos científicos nos anos de 2013 e 
2014. Pela avaliação de 2013, a EAD em Foco foi classificada no estrato B1 em Ensino, nossa melhor classificação, mas objetivamos ir além disso. Em geral, os periódicos científicos estão vinculados aos programas de pós-graduação, que por sua vez compõem cada uma das áreas de avaliação da Capes. Os critérios utilizados para classificar um periódico variam entre as diversas áreas. Os principais fatores utilizados são: constar em bases de indexação, periodicidade, quantidade de artigos publicados e diversidade institucional dos autores, entre outros.

É com grande satisfação que apresentamos o terceiro número do volume cinco da Revista EAD em Foco. Esta edição coroa o conjunto de conquistas obtidas recentemente, fruto de intenso período de trabalho de reformulação da revista. Antes de mais nada, somos gratos àqueles que se dedicaram à reestruturação da revista, apoiando-nos com suas ideias e, principalmente, executando ações específicas que possibilitaram, pela primeira vez na história da revista, a publicação de três números em um único ano.

Expressamos nossa gratidão aos membros do conselho editorial científico, oriundos dos quatros cantos de nosso Brasil - e de fora dele! -, que trabalharam de forma voluntária emitindo pareceres de avaliação dos originais submetidos à EAD em Foco. Foi um minucioso trabalho realizado às cegas, baseado em critérios de qualidade que garantem a idoneidade desta revista perante a comunidade científica. Ao final de todo este processo, os artigos ainda passam por uma revisão meticulosa realizada por uma equipe de profissionais especializados. São eles: Maria das Graças Ramos, Maria Elisa Silveira, Lícia Matos e Alexandre Alves, além da revisão de inglês por Diana Castellani e Vittorio Lo Bianco.

Agradecemos também ao apoio institucional provido pela Fundação Cecierj, nas pessoas das professoras Masako Oya Masuda, Elizabeth Soares Bastos e de nosso presidente, Carlos Bielschowsky, sem os quais não seria possível a edição da revista. Por último, e mais importante, fazemos honrosa menção aos autores, pesquisadores no campo da Educação a Distância, por confiarem seus estudos à avaliação e divulgação pela Revista EAD em Foco.

Este conjunto de conquistas nos impõe o desafio constante de afirmar a qualidade de nossa revista, por meio da eficiência e adequação nos processos de submissão, avaliação e edição, adicionando o recente aumento do número de submissões de novos 
manuscritos. Não obstante os desafios, como diziam os antigos navegadores, relembrados nos belos versos do poeta luso Fernando Pessoa: "navegar é preciso".

Naveguemos, ora pois!

Esteban Lopez Moreno, Luiz Gustavo Ribeiro Rolando Editores da Revista EAD em Foco 